\title{
miR-93-5p promotes insulin resistance to regulate type 2 diabetes progression in HepG2 cells by targeting HGF
}

\author{
MAN ZHOU, YILIN HOU, JUN WU, GUANGLI LI, PING CAO, WAN CHEN, LINGLI HU and DINGYUN GAN \\ Department of Endocrinology, Wuhan Third Hospital, Wuhan, Hubei 430060, P.R. China
}

Received June 15, 2020; Accepted January 4, 2021

DOI: $10.3892 / \mathrm{mmr} .2021 .11968$

\begin{abstract}
Insulin resistance is a common feature of type 2 diabetes mellitus (T2DM). However, the mechanisms underlying insulin resistance are not completely understood. The present study aimed to investigate the effect of microRNA (miR)-93-5p on insulin resistance in T2DM cells. Human hepatocellular carcinoma (HCC; HepG2) cells were cultured in medium with high glucose content $(30 \mathrm{mM}$ glucose) to establish an in vitro insulin-resistant cell model (IR group). Glucose consumption and glycogen synthesis assays were performed to assess glucose consumption and glycogen synthesis, respectively. By performing immunoprecipitation assays, the abundance of the Met-insulin receptor complex was detected in HepG2 cells. miR-93-5p and hepatocyte growth factor (HGF) mRNA expression levels were measured via reverse transcription-quantitative PCR, and HGF protein expression levels were measured via western blotting. A dual-luciferase reporter assay was conducted to investigate the interaction between miR-93-5p and HGF. Cell Counting Kit-8, BrdU and caspase-3 activity assays were performed to evaluate cell viability, proliferation and apoptosis, respectively, in insulin-resistant HepG2 cells following transfection with small interfering RNA-HGF, HGF overexpression vector, miR-93-5p mimic or miR-93-5p inhibitor. The results demonstrated that miR-93-5p expression was significantly increased and HGF expression was significantly decreased in HCC tissues isolated from patients with or without T2DM compared with adjacent healthy tissues isolated from patients without T2DM. Compared with the IR group, miR-93-5p overexpression significantly increased cell proliferation, glucose consumption and glycogen synthesis, but significantly inhibited apoptosis in insulin-resistant HepG2 cells. By contrast, compared with the IR group, HGF overexpression significantly inhibited cell
\end{abstract}

Correspondence to: Dr Dingyun Gan, Department of Endocrinology, Wuhan Third Hospital, 241 Pengliuyang Road, Wuchang, Wuhan, Hubei 430060, P.R. China

E-mail: gandingyun80@163.com

Key words: microRNA-93-5p, hepatocyte growth factor, type 2 diabetes, insulin resistance proliferation, glucose consumption and glycogen synthesis, but significantly enhanced cell apoptosis in insulin-resistant HepG2 cells. Following co-transfection with HGF overexpression vector and miR-93-5p mimic, miR-93-5p mimic-mediated induction of HepG2 cell proliferation, glucose consumption and glycogen synthesis in insulin-resistant HepG2 cells was inhibited. Collectively, the results of the present study indicated that miR-93-5p enhanced insulin resistance to regulate T2DM progression in HepG2 cells by targeting HGF.

\section{Introduction}

Diabetes mellitus refers to a complex metabolic syndrome that is primarily characterized by hyperglycemia, and aggravation of the disease can lead to symptoms, including weight loss, blurry vision, extreme fatigue and increased hunger (1). It was reported that there were $>400$ million individuals with diabetes worldwide in 2017 (2), with the majority of patients with diabetes suffering from type 2 diabetes mellitus (T2DM), which occurs when the body fully resists the production of insulin (3). The incidence rate of T2DM has increased rapidly in the last ten years in Asia (4), and it is estimated that $>642$ million individuals in Asia will be diagnosed with T2DM in 2040 (5). Insulin resistance majorly contributes to the development of T2DM (6). Hepatic cell dysfunction might directly induce insulin resistance, thereby leading to T2DM development (7). Although T2DM has been documented as one of the risk factors of human hepatocellular carcinoma (HCC), whether the occurrence of human HCC induces and aggravates insulin resistance has not been previously reported $(8,9)$. Moreover, the pathogeneses of T2DM and HCC are not completely understood. Therefore, identifying the molecular mechanism underlying the mutually promoting effect between T2DM and HCC would aid with the development of therapeutic strategies for the two diseases.

Hepatocyte growth factor (HGF) was first identified as a mitogen of hepatocytes that promoted hepatocyte proliferation and differentiation (10). In 2011, the HGF/Met axis was reported to facilitate hepatic glucose uptake and restrain hepatic glucose output, thus restoring insulin responsiveness in an insulin-resistant mouse model (11). Moreover, the HGF/Met axis was reported to be the key signaling pathway inhibited during hepatic steatosis and insulin resistance caused by mineralocorticoid receptor deficiency in macrophages (12). Another study suggested that HGF activation in liver tissues 
prevented insulin resistance (13). Nevertheless, the effect of HGF on insulin resistance and the molecule regulating the functions of HGF in the human HCC cell line model are yet to be explored.

MicroRNAs (miRNAs/miRs) are a class of single-stranded RNAs that are 18-25 nucleotides in length (14). Although they do not encode proteins, miRNAs suppress the expression of protein-coding genes at the post-transcriptional level by degrading target mRNAs or preventing mRNA translation, thereby affecting pathophysiological processes, including tumorigenesis, insulin resistance and the occurrence of T2DM (15-20). Several studies have investigated the role of miR-93-5p in human HCC formation. One study reported that miR-93-5p expression was upregulated in human HCC, where it exerted a positive effect on hepatoma progression (21). Similarly, another study suggested that miR-93-5p overexpression facilitated hepatoma occurrence and development by targeting PPARG coactivator $1 \alpha$ (22). In the present study, the bioinformatics analysis results revealed that miR-93-5p was a key aberrantly expressed miRNA in HCC tissues that might directly target HGF. Given the regulatory function of HGF in insulin resistance, investigating the role of miR-93-5p in insulin resistance and human $\mathrm{HCC}$ is important.

The HepG2 cell line is a human hepatic embryonal tumor cell line with a phenotype identical to hepatocytes (23). It has been reported that high level insulin treatment stimulates insulin receptors on the surface of HepG2 cells by $58 \%$, but the remaining receptors dampen insulin internalization (24). The decreased number of surface insulin receptors on HepG2 cells was positively related to the insulin level and stimulation duration, which indicated that HepG2 cells are an appropriate model for studying the mechanism underlying the pathogenesis of insulin resistance in vitro. The present study aimed to investigate whether miR-93-5p participated in insulin resistance and tumorigenesis by using an insulin-resistant HepG2 cell model. The results of the present study may provide a novel diagnostic and therapeutic strategy for T2DM and HCC.

\section{Materials and methods}

Bioinformatics analysis. The GSE84402 (25), GSE45050 (26) and GSE15652 (27) datasets, which were downloaded from Gene Expression Omnibus (GEO, https://www.ncbi.nlm.nih. gov/gds/), are mRNA expression microarrays involving liver cancer and T2DM. The GSE108724 dataset (28), which was downloaded from GEO, is a miRNA expression microarray involving liver cancer. Limma 3.26.8 (https://bioconductor. org/packages/release/bioc/html/limma.html) was employed to identify downregulated differentially expressed genes (DEGs) with an adjusted (adj.)P-value $<0.05$ and log fold change $(\log \mathrm{FC})<-1$. The upregulated differentially expressed miRNAs with an adj.P-value $<0.05$ and $\log F C>1$ were screened out using Limma 3.26.8. Gene Expression Profiling Interactive Analysis (GEPIA, http://gepia.cancer-pku.cn/index.html), an online tool, was further used to analyze gene expression in liver HCC (LIHC) tumor and non-tumor samples. StarBase (https://string-db.org/) was also employed to predict the miRNAs targeting the gene of interest. Venny 2.1.0 (https://bioinfogp.cnb.csic.es/tools/venny/) was applied to overlap the common genes and miRNAs.
Patient sample collection. A total of 62 patients (46-68 years old) diagnosed with HCC with T2DM $(\mathrm{n}=31)$ or without T2DM $(n=31)$ were recruited from Wuhan Third Hospital (Wuhan, China) between April 2015 and December 2019. HCC tissues and adjacent healthy hepatic tissues (distance from tumor margin, $\leq 3 \mathrm{~cm}$ ) confirmed by pathology were collected by performing a tumorectomy. Once the tissues were collected, the patients received first-line chemotherapy. All patients provided written informed consent. The present study was approved by the Ethics Committee of Wuhan Third Hospital (approval no. KY2020-015). The clinical characteristics of the patients are presented in Table I.

Cell culture and insulin-resistant cell model. The HepG2 cell line, which was identified as a human HCC cell line by STR profiling, was obtained from China Infrastructure of Cell Line Resources, Institute of Basic Medical Sciences, Chinese Academy of Medical Sciences. HepG2 cells were cultured in Minimum Essential Medium Eagles with Earle's Balanced Salts (MEM-EBSS; Table II) supplemented with 10\% FBS (cat. no. 10093; Gibco; Thermo Fisher Scientific, Inc.) and $1 \%$ non-essential amino acids (cat. no. 11140050; Gibco; Thermo Fisher Scientific, Inc.) at $37^{\circ} \mathrm{C}$ with $5 \% \mathrm{CO}_{2}$. To establish the insulin-resistant cell model, HepG2 cells were cultured for $48 \mathrm{~h}$ in high glucose content $[30 \mathrm{mM}$ glucose; insulin resistance group (IR)] at $37^{\circ} \mathrm{C}$ with $5 \% \mathrm{CO}_{2}$. In the control group (CON), HepG2 cells were cultured for $48 \mathrm{~h}$ in normal culture medium at $37^{\circ} \mathrm{C}$ with $5 \% \mathrm{CO}_{2}$.

Glucose consumption assay. Glucose concentrations in HepG2 cell culture medium were assessed using the Glucose Colorimetric Detection kit (Invitrogen; Thermo Fisher Scientific, Inc.). Briefly, HepG2 cells were seeded $\left(2 \times 10^{5}\right.$ cells/well) into a 96-well plate with five blank wells. Cells were cultured in high glucose solution $(30 \mathrm{mM})$. At $80 \%$ confluence, culture conditions were returned to normal culture conditions. Subsequently, $100 \mathrm{nM}$ insulin (Gibco; Thermo Fisher Scientific, Inc.) was added to cells and incubated for $15 \mathrm{~min}$ at $37^{\circ} \mathrm{C}$. Glucose consumption was detected at $0,4,8,12,24$ and $30 \mathrm{~h}$. Glucose consumption was calculated according to the following formula: Glucose concentration of blank wells - glucose concentration of cell-containing wells.

Glycogen synthesis assay. HepG2 cell glycogen synthesis was determined using the EnzyChrom Glycogen Assay kit (BioAssay Systems) according to the manufacturer's protocol. HepG2 cells were cultured in high glucose medium or normal glucose medium for $24 \mathrm{~h}$. Subsequently, cells were treated with $100 \mathrm{nM}$ insulin for $15 \mathrm{~min}$ at $37^{\circ} \mathrm{C}$. Cells were then harvested, lysed in lysis buffer (BioAssay Systems) and homogenized in $25 \mathrm{mM}$ citrate. Following centrifugation $\left(37^{\circ} \mathrm{C}, 10,000 \mathrm{x} \mathrm{g}, 5 \mathrm{~min}\right)$ to remove debris, the supernatant (10 $\mu \mathrm{l})$ was seeded into each well. Subsequently, $90 \mu \mathrm{l}$ working reagent (containing $87 \mu \mathrm{l}$ Assay Buffer, $1 \mu \mathrm{l}$ Enzyme A, $1 \mu \mathrm{l}$ Enzyme B and $1 \mu 1$ Dye Reagent) was added to each reaction well and incubated at room temperature for $30 \mathrm{~min}$. The optical density at a wavelength of $570 \mathrm{~nm}$ was examined using a microplate reader. Glycogen concentrations were calculated according to the standard curve. 
Table I. Clinical characteristics of 62 patients with hepatocellular carcinoma.

\begin{tabular}{|c|c|}
\hline Characteristic & Number of patients $(n=62)$ \\
\hline \multicolumn{2}{|l|}{ Age, n (\%) } \\
\hline$\leq 55$ & $34(55)$ \\
\hline$>55$ & $28(45)$ \\
\hline \multicolumn{2}{|l|}{ Sex, n $(\%)$} \\
\hline Male & $33(53)$ \\
\hline Female & $29(47)$ \\
\hline \multicolumn{2}{|c|}{ Tumor size $(\mathrm{cm}), \mathrm{n}(\%)$} \\
\hline$\geq 5$ & $30(48)$ \\
\hline$<5$ & $32(52)$ \\
\hline \multicolumn{2}{|c|}{ Histologic grade, n (\%) } \\
\hline G1 & $20(32)$ \\
\hline G2 & $26(42)$ \\
\hline G3 & $16(26)$ \\
\hline \multicolumn{2}{|c|}{ TNM stage (43), n (\%) } \\
\hline I-II & $36(58)$ \\
\hline III-IV & $26(42)$ \\
\hline \multicolumn{2}{|l|}{ T2DM } \\
\hline Absence, n (\%) & $31(50)$ \\
\hline HOMA-IR & $1.8 \pm 0.5$ \\
\hline HbA1c $(\%)$ & $7.4 \pm 0.3$ \\
\hline Presence, n (\%) & $31(50)$ \\
\hline HOMA-IR & $4.3 \pm 0.9$ \\
\hline HbA1c $(\%)$ & $5.1 \pm 0.4$ \\
\hline
\end{tabular}

T2DM, type 2 diabetes mellitus; HOMA-IR, Homeostatic Model Assessment of Insulin Resistance; HbA1c, hemoglobin A1c.

Reverse transcription-quantitative PCR (RT-qPCR). Total RNA was extracted from tissues and cells using RNAiso reagents (Takara Bio, Inc.) according to the manufacturer's protocol. Total RNA was quantified using a NanoDrop2000 spectrophotometer (Thermo Fisher Scientific, Inc.). Subsequently, RNA $(2 \mu \mathrm{g})$ was reverse transcribed into cDNA using the One Step PrimeScript miRNA cDNA synthesis kit (Takara Bio, Inc.) at $37^{\circ} \mathrm{C}$ for $20 \mathrm{~min}$ and $80^{\circ} \mathrm{C}$ for $2 \mathrm{~min}$ or the PrimeScript ${ }^{\mathrm{TM}}$ Double Strand cDNA Synthesis kit (Takara Bio, Inc.) at $65^{\circ} \mathrm{C}$ for $5 \mathrm{~min}$ and $42^{\circ} \mathrm{C}$ for $1 \mathrm{~h}$. Next, qPCR was performed using ChamQ Universal SYBR qPCR Master Mix (Vazyme BioTech Co., Ltd.) with thermocycling conditions as follows: Initial denaturation at $95^{\circ} \mathrm{C}$ for $30 \mathrm{sec}, 40$ cycles at $95^{\circ} \mathrm{C}$ for $5 \mathrm{sec}$ and $60^{\circ} \mathrm{C}$ for $20 \mathrm{sec}$. The sequences of the primers used for $\mathrm{qPCR}$ are presented in Table III. miRNA and mRNA expression levels were quantified using the $2^{-\Delta \Delta C q}$ method (29) and normalized to the internal reference genes U6 and GAPDH, respectively.

Cell transfection. The HGF overexpression (OE) vector (OE-HGF), HGF small interfering RNA (si; si-HGF), miR-93-5p mimic, miR-93-5p inhibitor and their corresponding negative controls (NCs) were purchased from Shanghai GenePharma Co., Ltd. (Table SI). pcDNA3.1 empty
Table II. Formulation of Minimum Essential Medium Eagles with Earle's Balanced Salts.

\begin{tabular}{lc} 
A, Inorganic salts & \\
\hline Component & Quantity (g/l) \\
\hline $\mathrm{CaCl}_{2}$ (anhydrous) & 0.20000 \\
$\mathrm{MgSO}_{4}$ (anhydrous) & 0.09767 \\
$\mathrm{KCl}$ & 0.40000 \\
$\mathrm{NaHCO}_{3}$ & 1.50000 \\
$\mathrm{NaCl}_{\mathrm{NaH}} \mathrm{PO}_{4} \cdot \mathrm{H}_{2} \mathrm{O}$ & 6.80000 \\
& 0.14000
\end{tabular}

B, Vitamins

\begin{tabular}{lc}
\hline Component & Quantity $(\mathrm{g} / \mathrm{l})$ \\
\hline Choline Chloride & 0.00100 \\
Folic Acid & 0.00100 \\
myo-Inositol & 0.00200 \\
Nicotinamide & 0.00100 \\
D-Pantothenic Acid (hemicalcium) & 0.00100 \\
Pyridoxine $\cdot \mathrm{HCl}$ & 0.00100 \\
Riboflavin & 0.00010 \\
Thiamine $\cdot \mathrm{HCl}$ & 0.00100
\end{tabular}

C, Amino acids

\begin{tabular}{lc}
\hline Component & Quantity $(\mathrm{g} / \mathrm{l})$ \\
L-Alanine & 0.00890 \\
L-Arginine $\cdot \mathrm{HCl}$ & 0.12640 \\
L-Asparagine $\cdot \mathrm{H}_{2} \mathrm{O}$ & 0.01500 \\
L-Aspartic Acid & 0.01330 \\
L-Cystine·2HCl & 0.03120 \\
L-Glutamic Acid & 0.01470 \\
L-Glutamine & 0.29200 \\
Glycine & 0.00750 \\
L-Histidine $\cdot \mathrm{HCl} \cdot \mathrm{H}_{2} \mathrm{O}$ & 0.04190 \\
L-Isoleucine & 0.05250 \\
L-Leucine & 0.05250 \\
L-Lysine $\cdot \mathrm{HCl}$ & 0.07250 \\
L-Methionine & 0.01500 \\
L-Phenylalanine & 0.03250 \\
L-Proline & 0.01150 \\
L-Serine & 0.01050 \\
L-Threonine & 0.04760 \\
L-Tryptophan & 0.01000 \\
L-Tyrosine $2 \mathrm{Na} \cdot 2 \mathrm{H}_{2} \mathrm{O}$ & 0.05190 \\
L-Valine & 0.04680
\end{tabular}

D, Other

\begin{tabular}{lc} 
Component & Quantity $(\mathrm{g} / \mathrm{l})$ \\
\hline D-Glucose & 1.00000 \\
Phenol Red, Sodium Salt & 0.01000 \\
Sodium Pyruvate & 0.11000 \\
\hline
\end{tabular}


vector was used as the NC for OE-HGF. HepG2 cells were seeded $\left(2 \times 10^{4}\right.$ cells/well) into a 6-well plate. Subsequently, cells were transfected with OE-HGF $(2.5 \mu \mathrm{g})$, si-HGF $(2.5 \mu \mathrm{g})$, miR-93-5p mimic (50 nM), miR-93-5p inhibitor (50 $\mathrm{nM})$ or the corresponding NCs $(50 \mathrm{nM})$ using Lipofectamine ${ }^{\circledR} 3000$ Transfection Reagent (Invitrogen; Thermo Fisher Scientific, Inc.) at $37^{\circ} \mathrm{C}$ for $48 \mathrm{~h}$. The transfection efficiency and the subsequent assays were performed $48 \mathrm{~h}$ after transfection. Cells in the NC group were transfected with mimic-NC and inhibitor-NC, or empty vector and si-NC due to the similar transfection efficiency of their NC (Figs. S1 and S2).

Western blotting. Total protein was extracted from tissue lysates or HepG2 cells using RIPA lysis buffer (Beyotime Institute of Biotechnology) according to the manufacturer's protocol. Protein concentrations were determined using the BCA protein assay kit (Beyotime Institute of Biotechnology). Proteins $(10 \mu \mathrm{g})$ were separated via $10 \%$ SDS-PAGE, and subsequently transferred onto PVDF membranes (EMD Millipore). Following blocking with $5 \%$ skimmed milk for $1 \mathrm{~h}$ at $25^{\circ} \mathrm{C}$, the membranes were washed three times with PBS. Subsequently, the membranes were incubated with anti-HGF (1:500; cat. no. ab83760; Abcam) and anti-GAPDH (1:5,000; cat. no. ab181602; Abcam) primary antibodies at $4^{\circ} \mathrm{C}$ overnight. After washing with PBS, the membranes were incubated with a Goat Anti-Rabbit IgG H\&L secondary antibody (1:5,000; cat. no. ab205718; Abcam) for $1 \mathrm{~h}$ at $25^{\circ} \mathrm{C}$. Protein bands were visualized using the ECL Substrate kit (cat. no. ab133406; Abcam). Protein expression levels were semi-quantified using Image-Pro Plus software (version 6.0; Media Cybernetics, Inc.) with GAPDH as the loading control.

Immunoprecipitation. To detect the Met-INSR complex in HepG2 cells, the Protein A/G Immunoprecipitation kit (Beijing Solarbio Science \& Technology Co., Ltd.) was used according to the manufacturer's protocol. HepG2 cells were cultured in high glucose or normal glucose medium for $24 \mathrm{~h}$. Subsequently, cells were treated with $100 \mathrm{nM}$ insulin for $15 \mathrm{~min}$ at $37^{\circ} \mathrm{C}$. Cells were harvested and lysed using $200 \mu \mathrm{l}$ RIPA lysis buffer (Beyotime Institute of Biotechnology). After lysing the cells for $10 \mathrm{~min}$, the cells were centrifuged at $10,000 \mathrm{x} \mathrm{g}$, $4^{\circ} \mathrm{C}$ for 5 min. INSR- $\beta$ antibody-conjugated magnetic beads (1:30; cat. no. ab227831; Abcam) were prepared, added to the whole-cell protein extracts and incubated overnight at $4^{\circ} \mathrm{C}$. Immunoprecipitates were collected using a magnetic separator and washed three times with lysis buffer. Subsequently, immunoprecipitates were separated via SDS-PAGE and subjected to western blotting with INSR- $\beta$ (1:1,000; cat. no. ab227831; Abcam) and HGF antibodies as described above.

Dual-luciferase reporter assay. The wild-type (WT) sequence of HGF 3'UTR (HGF-WT) and the mutant (MUT) type sequence of HGF 3'UTR (HGF-MUT) were synthesized by GeneCreate. HGF-MUT was generated by altering the sequence of the binding sites from 'CACGAAC' to 'GUGCUU' and 'CACUUU' to 'GUGAAA'. Subsequently, HGF-WT and HGF-MUT were cloned into the pmiR-GLO vector (Promega Corporation). HepG2 cells were co-transfected with $2.5 \mu \mathrm{g}$ HGF-WT or HGF-MUT and $50 \mathrm{nM}$ miR-93-5p mimic or mimic NC using Lipofectamine 3000 reagent. At
$48 \mathrm{~h}$ post-transfection, cells were treated with lysis buffer (GeneCreate). Relative luciferase activities were detected with a Dual-Luciferase Reporter Assay System (Promega Corporation) and normalized against Renilla luciferase activity.

RNA pull-down assay. Both miR-93-5p mimic-biotin (Bio; Bio-miR-93-5p, 5'-CAAAGUGCUGUUCGUGCAGGUAGbiotin-3') and mimic-Bio-NC (Bio-NC, 5'-UCACAACCUCCU AGAAAGAGUAGA-biotin-3') were synthesized by Guangzhou RiboBio Co., Ltd. HepG2 cells were cultured in a 6-well plate. At $70-80 \%$ confluence, cells were transfected with $50 \mathrm{nM}$ Bio-miR-93-5p mimic or Bio-NC for $48 \mathrm{~h}$ using Lipofectamine 3000 reagent at $37^{\circ} \mathrm{C}$. Subsequently, HepG2 cells were collected and treated with Cell Lysis Buffer (EMD Millipore). Proteinase K solution and DNase I (EMD Millipore) were added to remove the protein and DNA at $4^{\circ} \mathrm{C}$ for $20 \mathrm{~min}$. After the protein and DNA were removed, samples were incubated with streptavidin magnetic beads (Invitrogen; Thermo Fisher Scientific, Inc.) at $4^{\circ} \mathrm{C}$ for $4 \mathrm{~h}$. Streptavidin magnetic beads were absorbed using a magnetic grate (Thermo Fisher Scientific, Inc.). Subsequently, RNA was extracted and evaluated via RT-qPCR.

Cell Counting Kit-8 (CCK-8) assay. HepG2 cells were seeded into a 96 -well plate at a density of $2 \times 10^{4}$ cells $/ \mathrm{ml}$. At $12,24,48$ and $72 \mathrm{~h}$ post-transfection, cell proliferation was assessed by performing the CCK- 8 assay (Abcam). Briefly, $10 \mu \mathrm{l}$ CCK- 8 solution was added to each well and incubated at $37^{\circ} \mathrm{C}$ for $4 \mathrm{~h}$. The optical density was measured at a wavelength of $450 \mathrm{~nm}$ using a microplate reader (BioTek Instruments, Inc.).

BrdU cell proliferation assay. BrdU Cell Proliferation Assay kit (cat. no. 6813; Cell Signaling Technology, Inc.) was purchased to perform the BrdU cell proliferation assay. HepG2 cells $\left(2 \times 10^{4}\right.$ cells $\left./ \mathrm{ml}\right)$ were seeded into a 96 -well plate. Following culture for $48 \mathrm{~h}$ at $37^{\circ} \mathrm{C}$, the culture medium was replaced with $\mathrm{BrdU}$ solution and incubated for $1 \mathrm{~h}$. Subsequently, the culture medium was replaced with $100 \mu \mathrm{l}$ fixing/denaturing solution and incubated for $30 \mathrm{~min}$ at room temperature. The solution was removed and the BrdU detection antibody (1:100) was added to the cells for $1 \mathrm{~h}$ at room temperature. Subsequently, anti-mouse IgG secondary antibody (1:100) and HRP solution were successively added to the cells to induce the chromogenic reaction at $25^{\circ} \mathrm{C}$. Absorbance was measured at a wavelength of $450 \mathrm{~nm}$ using a microplate reader.

Caspase-3 activity assay. To assess cell apoptosis, the caspase-3 Activity Assay kit (Beyotime Institute of Biotechnology) was used. At $48 \mathrm{~h}$ post-transfection, 2.5\% trypsin (Gibco; Thermo Fisher Scientific, Inc.) was used for the digestion and collection of cells. Subsequently, total protein was extracted from cells using lysis solution. Then, $40 \mu \mathrm{l}$ buffer solution, $50 \mu \mathrm{l}$ sample and $10 \mu \mathrm{l}$ Ac-DEVD-pNA were gently mixed and then incubated for $2 \mathrm{~h}$ at $37^{\circ} \mathrm{C}$. Absorbance was measured at a wavelength of $405 \mathrm{~nm}$ using a microplate reader.

Statistical analysis. Statistical analyses were performed using SPSS software (version 23.0; IBM Corp.). For each experiment, three independent tests were performed. Data 
Table III. Sequences of primers used for reverse transcription-quantitative PCR.

Gene

\section{HGF}

GAPDH

miR-93-5p

U6
Primer sequences $\left(5^{\prime} \rightarrow 3^{\prime}\right)$
F: GTAAATGGGATTCCAACACGAACAA
R: TGTCGTGCAGTAAGAACCCAACTC
F: GGGTGGTGCAAAGAGAGTCA
R: GCAGGAGGCATTGCTTACAAC
F: ACACTCCAGCTGGGCAAAGTGCTGTTCGTGC
R: CTCAACTGGTGTCGTGGAGTCGGCAATTCAGTTGAGCTACCTGC
F: GATTAGCATGGCCCCTGC
R: GTCGTATCCAGTGCGTGTCGTCCAGTCGGCAATTGCACTGGATACGACAAAATATG

HGF, hepatocyte growth factor; miR, microRNA; F, forward; R, reverse.

are presented as the mean \pm SD. An unpaired Student's t-test was used to analyze comparisons between two groups. One-way or two-way ANOVA followed by Tukey's post hoc test were used to analyze comparisons among multiple groups. Pearson's correlation coefficient analysis was performed to assess the correlation between miR-93-5p expression and HGF expression. $\mathrm{P}<0.05$ was considered to indicate a statistically significant difference.

\section{Results}

HGF is a biomarker of insulin resistance. To analyze downregulated DEGs associated with liver cancer and T2DM (adj.P <0.05 and $\log \mathrm{FC}<-1$ ), three datasets (GSE8442, GSE45050 and GSE15653) were downloaded from GEO. After performing Venny 2.1.0 analysis, the only overlapping gene among all three microarrays was HGF (Fig. 1A). Subsequently, GEPIA was used to assess HGF expression in LIHC. The GEPIA results demonstrated that HGF expression was significantly reduced in LIHC samples compared with non-tumor samples (Fig. 1B). RT-qPCR analysis of HGF mRNA expression levels in HCC and adjacent healthy samples from patients with HCC with or without T2DM was performed. The results demonstrated that HGF expression was significantly lower in both HCC tissues and adjacent healthy tissues isolated from patients with T2DM compared with adjacent healthy tissues isolated from patients without T2DM (Fig. 1C).

Furthermore, western blotting was performed to measure HGF protein expression levels in HCC tissues and adjacent healthy tissues isolated from patients with or without T2DM. The results demonstrated that HGF protein expression levels were significantly lower in HCC tissues isolated from patients with or without T2DM and in adjacent healthy tissues isolated from patients with T2DM compared with adjacent healthy tissues isolated from patients without T2DM (Fig. 1D). Subsequently, HepG2 cells were treated with glucose $(30 \mathrm{mM})$ to establish an insulin-resistant model in vitro. Glucose consumption was measured to assess the insulin-resistant model. The results demonstrated that compared with the $0 \mathrm{~h}$ time point group, glucose consumption significantly peaked within $1 \mathrm{~h}$ after adding insulin. Compared with the $0 \mathrm{~h}$ time point, glucose consumption significantly decreased to a minimum level after $12 \mathrm{~h}$ and then significantly increased after $24 \mathrm{~h}$ (Fig. 1E); therefore, $24 \mathrm{~h}$ was selected as the insulin intervention period for the HepG2 insulin-resistant model.

To further verify insulin resistance in HepG2 cells treated with high glucose concentration, insulin-stimulated glucose consumption and glycogen synthesis in HepG2 cells treated with high glucose (IR group) or normal (CON group) culture medium for $24 \mathrm{~h}$ were compared. The results demonstrated that both glucose consumption and glycogen synthesis were significantly decreased in the IR group compared with the CON group, which indicated the occurrence of insulin resistance in HepG2 cells treated in medium with high glucose concentration (Fig. 1F and G). It has been reported that HGF regulates hepatic glucose metabolism via the $\mathrm{HGF} / \mathrm{Met}$ axis. As the receptor of HGF, Met can transmit the HGF signal to directly engage INSR and form a Met-INSR hybrid complex, which in turn activates a series of insulin responses to promote glucose catabolism (11). In this context, the abundance of the Met-INSR complex can serve as a marker influencing an insulin response (30). By performing immunoprecipitation assays, the results demonstrated that there was an abundance of the Met-INSR complex in the IR group. The abundance of the Met-INSR complex was significantly lower by $\sim 50 \%$ in the IR group compared with the CON group, suggesting that insulin sensitivity was reduced in the IR group (Fig. 1H). Subsequently, RT-qPCR and western blotting were performed to detect the expression levels of HGF in the CON and IR groups in HepG2 cells. HGF mRNA and protein expression levels were significantly decreased in the IR group compared with the CON group (Fig. 1I and J). Overall, the results suggested that HGF was associated with insulin resistance and that it might serve as a biomarker of insulin resistance in HepG2 cells.

HGF inhibits insulin resistance and cell proliferation, but promotes cell apoptosis in HepG2 cells. Based on the hypothesis that the HGF gene might serve as a biomarker of insulin resistance in HepG2 cells, the role of HGF in insulin-resistant HepG2 cells was investigated. HepG2 cells transfected with si-HGF or OE-HGF were cultured with $30 \mathrm{mM}$ glucose (IR + si-HGF or IR + OE-HGF, respectively). For the control group, HepG2 cells were cultured in normal culture medium. Western blotting and RT-qPCR were performed to detect transfection efficiency. si-HGF significantly reduced HGF mRNA 
A

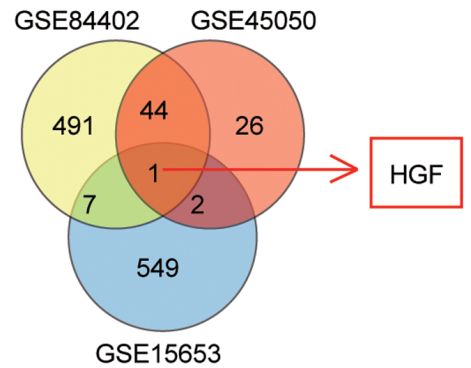

B

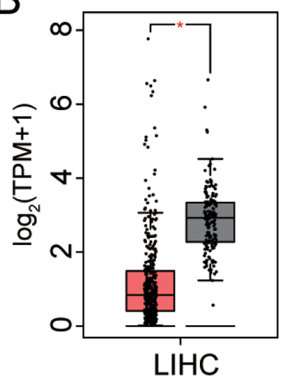

(num $(\mathrm{T})=369 ; \operatorname{num}(\mathrm{N})=160$ )
C $\rightarrow$ adjacent tissues $\rightarrow$ ** HCC tissues

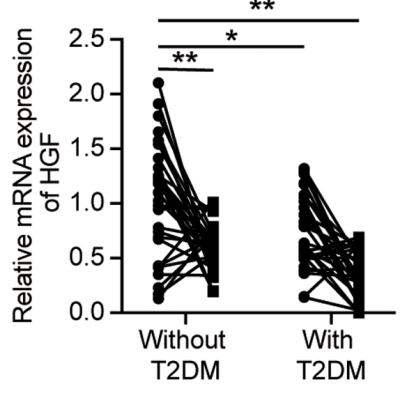

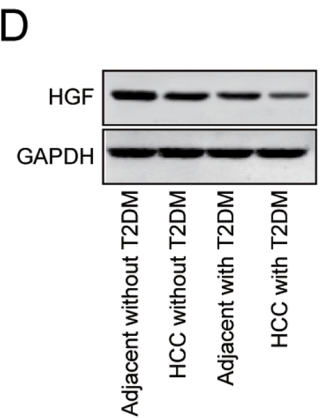

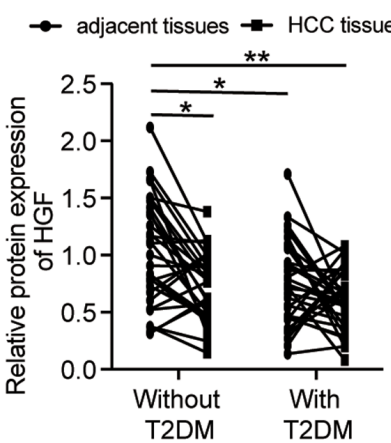

E
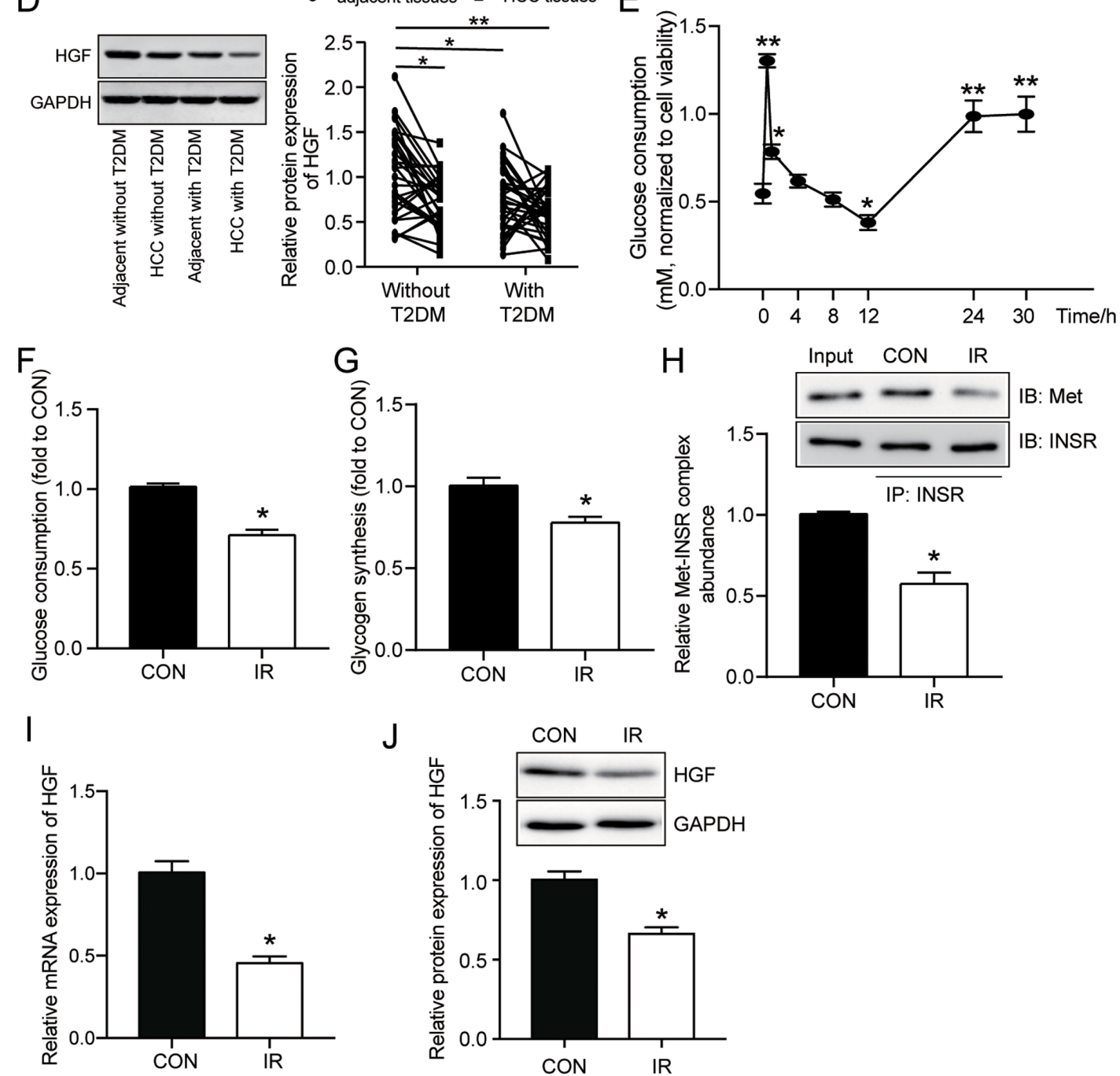

Figure 1. HGF is a biomarker of insulin resistance. (A) HGF was the only overlapping gene among the GSE84402, GSE45050 and GSE15653 datasets. GSE84402, GSE45050 and GSE15653 profiles are mRNA microarrays involved in liver cancer and T2DM. (B) By performing Gene Expression Profiling Interactive Analysis, the results indicated that HGF expression was reduced in LIHC samples. HGF (C) mRNA and (D) protein expression levels in HCC tissues and adjacent healthy tissues isolated from patients with or without T2DM were measured via RT-qPCR and western blotting, respectively. (E) Period of glucose consumption in HepG2 cells. (F) Glucose consumption in HepG2 cells with or without insulin resistance was examined by performing glucose consumption assays. (G) Glycogen synthesis in HepG2 cells with or without insulin resistance was examined by performing glycogen synthesis assays. (H) Met-INSR complex abundance in insulin-resistant HepG2 cells was detected via immunoprecipitation assays. HGF (I) mRNA and (J) protein expression levels in HepG2 cells with or without insulin resistance were detected via RT-qPCR and western blotting, respectively. Data are presented as the mean \pm SD. ${ }^{*} \mathrm{P}<0.05$ and $^{* *} \mathrm{P}<0.001$ vs. CON. HGF, hepatocyte growth factor; LIHC, liver hepatocellular carcinoma; T2DM, type 2 diabetes mellitus; RT-qPCR, reverse transcription-quantitative PCR; Met-INSR, Met-insulin receptor; CON, normal culture; IR, insulin resistance; HCC, hepatocellular carcinoma; IB, immunoblotting; IP, immunoprecipitation; T, tumor; N, non-tumor.

and protein expression levels by $70 \%$ in insulin-resistant HepG2 cells compared with the IR group (Fig. 2A and B). Moreover, OE-HGF significantly increased HGF mRNA expression in insulin-resistant $\mathrm{HepG} 2$ cells by $>200 \%$ compared with the IR group (Fig. 2A). The western blotting results demonstrated that OE-HGF also significantly increased the protein expression levels of HGF in insulin-resistant HepG2 cells to a level almost twice as high compared with the IR group (Fig. 2B). Consistent 

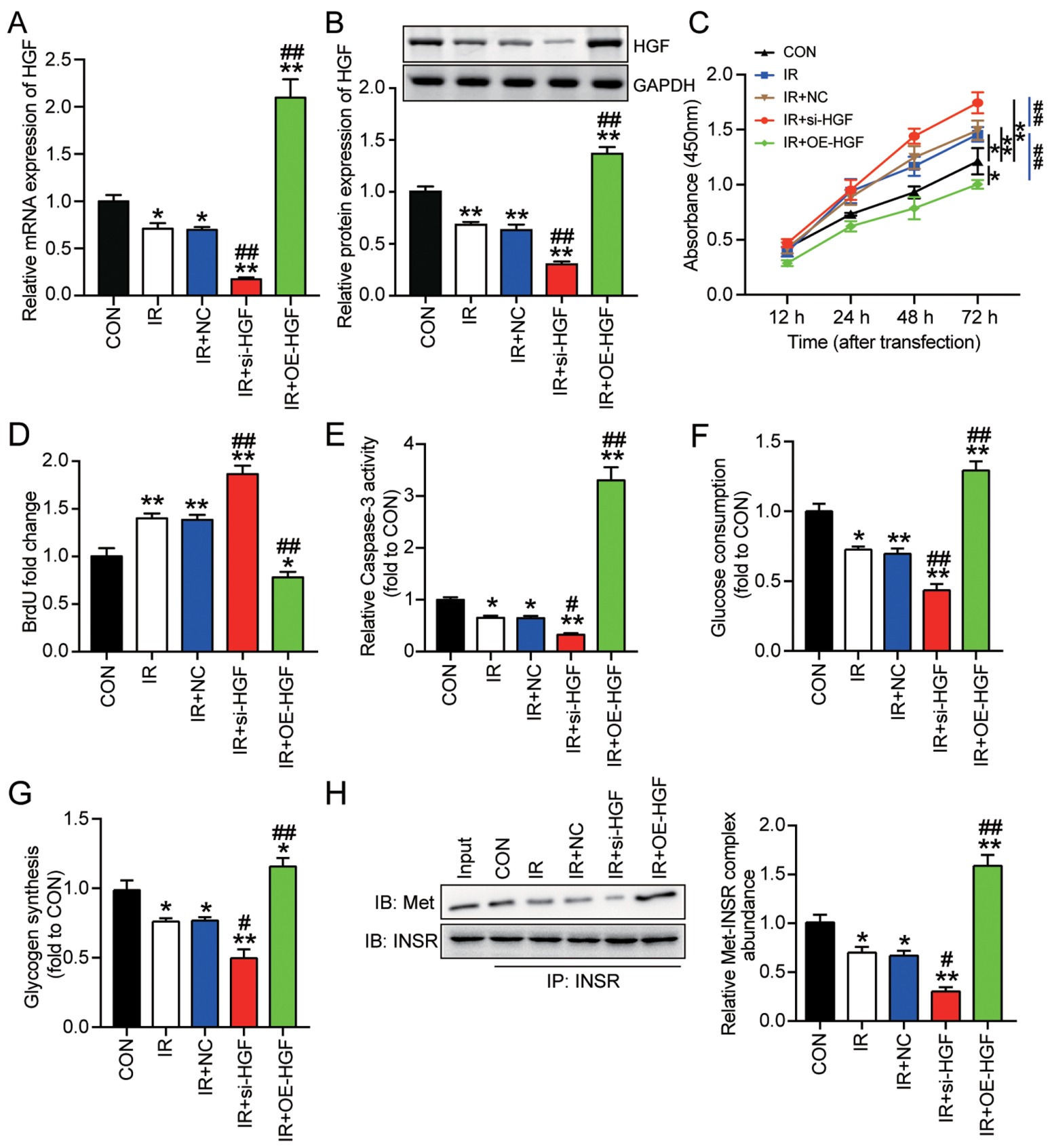

$\mathrm{H}$
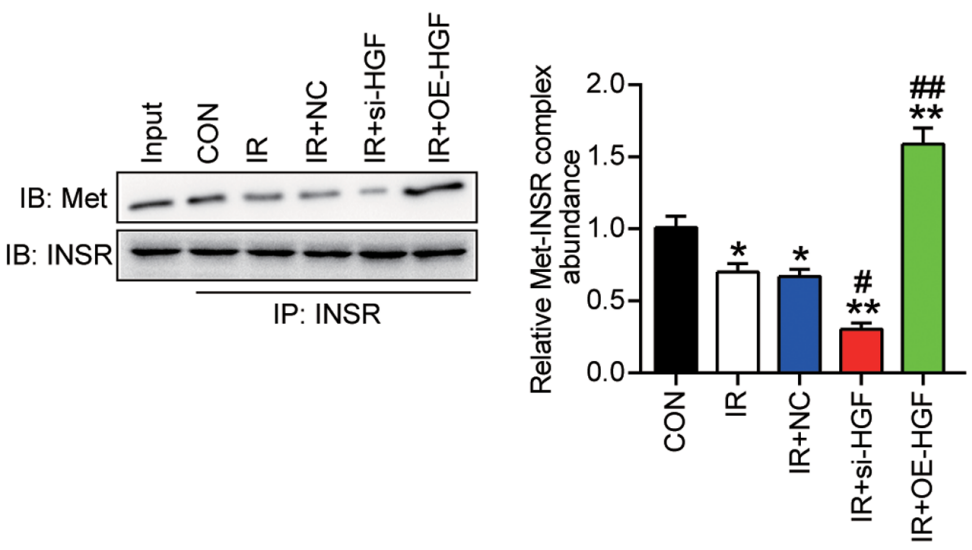

Figure 2. Effect of HGF on insulin resistance and tumorigenesis in HepG2 cells. Insulin-resistant HepG2 cells were transfected with si-HGF or OE-HGF. HGF (A) mRNA and (B) protein expression levels were measured via reverse transcription-quantitative PCR and western blotting, respectively. Cell (C) viability, (D) proliferation, (E) apoptosis, (F) glucose consumption and (G) glycogen synthesis were assessed by performing Cell Counting Kit-8, BrdU, caspase-3 activity, glucose consumption and glycogen synthesis assays, respectively. (H) Met-INSR complex abundance was assessed by performing immunoprecipitation assays. Data are presented as the mean $\pm \mathrm{SD}$. ${ }^{*} \mathrm{P}<0.05$ and ${ }^{* *} \mathrm{P}<0.001$ vs. CON; ${ }^{*} \mathrm{P}<0.05$ and ${ }^{\# \#} \mathrm{P}<0.001$ vs. IR. HGF, hepatocyte growth factor; si, small interfering RNA; OE, overexpression; Met-INSR, Met-insulin receptor; CON, blank control; IR, insulin resistance; NC, negative control (mimic-NC + inhibitor-NC); IB, immunoblotting; IP, immunoprecipitation.

with aforementioned results in insulin-resistant cells, control HepG2 cells (non-IR) transfected with si-HGF displayed significantly reduced HGF mRNA and protein expression levels, whereas transfection with OE-HGF significantly elevated HGF mRNA and protein expression levels compared with the CON and combined $\mathrm{NC}$ groups (Fig. S1). The aforementioned results suggested high transfection efficiency of si-HGF and OE-HGF in control and insulin-resistant HepG2 cells.

In terms of insulin resistance, OE-HGF significantly suppressed HepG2 cell viability compared with the IR and CON groups (Fig. 2C). By contrast, si-HGF significantly enhanced HepG2 cell viability compared with the IR and CON groups. A BrdU assay was performed to assess HepG2 cell proliferation. Furthermore, OE-HGF significantly suppressed cell proliferation by $40 \%$, whereas si-HGF significantly enhanced cell proliferation by $\sim 30 \%$ compared with the IR group (Fig. 2D). The caspase-3 activity assay results demonstrated that si-HGF significantly decreased cell apoptosis by $50 \%$, whereas OE-HGF significantly enhanced cell apoptosis by 5 -fold compared with the IR group (Fig. 2E). Similarly, compared with the IR group, glucose consumption and glycogen synthesis were significantly decreased by $30 \%$ in 
the IR + si-HGF group, but significantly increased by $40 \%$ in the IR + OE-HGF group (Fig. 2F and G).

To further determine the effect of HGF on insulin resistance, Met-INSR complex abundance in HepG2 cells under different treatment conditions was determined. HGF knockdown significantly decreased Met-INSR complex abundance by $50 \%$, but HGF overexpression significantly increased Met-INSR complex abundance by 2 -fold increase in insulin-resistant HepG2 cells compared with the IR group (Fig. 2H). Overall, the results indicated the inhibitory effect of HGF on insulin resistance and tumorigenesis in HepG2 cells.

HGF is a downstream target gene of miR-93-5p in HepG2 cells. To identify the key miRNA that participated in insulin sensitivity by targeting HGF, the GSE108724 miRNA expression microarray was used to identify upregulated miRNAs in liver cancer. starBase was also used to identify miRNAs that bound to HGF 3'UTR. miR-93-5p was the only miRNA that overlapped between the analysis of the GSE108724 dataset and the starBase analysis (Fig. 3A). Based on the starBase results, it was hypothesized that miR-93-5p might target HGF; therefore, WT and MUT sequences of HGF 3'UTR were constructed (Fig. 3B). The dual-luciferase reporter assay results demonstrated that miR-93-5p mimic significantly suppressed the luciferase activity of HGF-WT by $\sim 50 \%$ compared with the mimic NC group, which further indicated that miR-93-5p targeted HGF in insulin-resistant HepG2 cells (Fig. 3C). In addition, the RNA pull-down assay results demonstrated that that miR-93-5p mimic effectively pulled down HGF (Fig. 3D).

Although miR-93-5p expression was significantly higher in HCC tissues compared with adjacent healthy tissues without T2DM, it was not significantly different between adjacent healthy tissues isolated from patients with T2DM and adjacent healthy tissues isolated from patients without T2DM (Fig. 3E). Subsequently, a correlation analysis between miR-93-5p expression and HGF expression was conducted. The results demonstrated that miR-93-5p expression was negatively correlated with HGF expression (Fig. 3F). Furthermore, in insulin-resistant HepG2 cells, miR-93-5p inhibitor significantly downregulated miR-93-5p expression by $\sim 70 \%$, whereas miR-93-5p mimic significantly increased miR-93-5p expression by 2.5 -fold compared with the CON group or combined NC group (Figs. 3G and S2). Moreover, miR-93-5p inhibitor significantly increased HGF protein expression levels in insulin-resistant HepG2 cells by $>50 \%$, whereas miR-93-5p mimic significantly suppressed HGF expression by $\sim 50 \%$ compared with the CON group (Fig. $3 \mathrm{H}$ ).

miR-93-5p promotes insulin resistance and the progression of HepG2 cells by restraining HGF. To investigate whether miR-93-5p promoted insulin resistance in HepG2 cells, several experiments were conducted. HepG2 cells co-transfected with miR-93-5p mimic or OE-HGF + miR-93-5p mimic were cultured with in high concentration glucose (IR + mimic or $\mathrm{IR}+\mathrm{OE}-\mathrm{HGF}+$ mimic, respectively). RT-qPCR and western blotting were performed to detect HGF mRNA and protein expression levels following miR-93-5p or HGF overexpression. miR-93-5p mimic significantly downregulated HGF mRNA and protein expression levels in insulin-resistant HepG2 cells compared with the IR group. However, co-transfection of
miR-93-5p mimic and OE-HGF resulted in HGF expression levels in insulin-resistant HepG2 cells that were comparable with the IR group (Fig. 4A and B). Based on the CCK-8 assay results, HepG2 cell viability was significantly increased by miR-93-5p mimic compared with the IR group (Fig. 4C). However, co-transfection of OE-HGF and miR-93-5p mimic restored HepG2 cell viability to a similar level compared with the IR group. Similarly, the BrdU assay results demonstrated that HepG2 cell proliferation was significantly increased by $22 \%$ by miR-93-5p mimic compared with the IR group, which was reversed by co-transfection with OE-HGF (Fig. 4D).

Furthermore, the caspase-3 activity assay results demonstrated that miR-93-5p mimic significantly decreased HepG2 cell apoptosis under insulin resistance conditions by $\sim 30 \%$ compared with the IR group (Fig. 4E). Co-transfection of miR-93-5p mimic and OE-HGF induced similar levels of cell apoptosis in insulin-resistant HepG2 cells compared with the IR group. miR-93-5p mimic also significantly reduced glucose consumption and glycogen synthesis in insulin-resistant HepG2 cells compared with the IR group, but co-transfection with OE-HGF reversed miR-93-5p mimic-mediated effects (Fig. 4F and G). Moreover, miR-93-5p mimic significantly downregulated the abundance of the Met-INSR complex by $50 \%$ in insulin-resistant HepG 2 cells compared with the IR group, and co-transfection with OE-HGF reversed miR-93-5p mimic-mediated effects (Fig. 4H). Overall, the results demonstrated the inhibitory effect of HGF on insulin resistance and tumorigenesis in HepG2 cells. Furthermore, the results indicated that miR-93-5p enhanced insulin resistance and the progression of HepG 2 cells by inhibiting HGF.

\section{Discussion}

T2DM is a serious health condition characterized by high blood sugar and can trigger the development of other diseases, including HCC (8). Therefore, identifying molecular targets that can neutralize the negative effects of T2DM is important. Despite displaying different pathogeneses, T2DM has a mutually reinforcing effect with HCC (8). By identifying the molecular mechanism underlying insulin resistance in cells with HCC important, patients with $\mathrm{HCC}$ can be effectively protected against T2DM. In the present study, miR-93-5p expression was significantly increased and HGF expression was significantly decreased in HCC tissues isolated from patients with or without T2DM compared with adjacent healthy tissues isolated from patients without T2DM. The present study indicated that miR-93-5p could accelerate the tumor phenotype of HepG2 cells and promote insulin resistance in HepG2 cells by directly targeting HGF.

In the case of human HCC, the homeostasis of the liver is not well regulated, resulting in impaired metabolic function, including dysregulated glucose metabolism, which further leads to insulin resistance and T2DM (31). HGF, the dominant molecule activating Met signaling, has been widely reported to display cancer suppressive effects (32-34). However, the role of HGF in HCC is not completely understood. Following injury, HGF is a key factor in the maintenance of hepatic homeostasis (35), suggesting that HGF could serve as a putative factor in the prevention of insulin resistance and T2DM. Similarly, previous studies reported that HGF could stimulate glucose uptake, and protect against obesity and insulin 
A

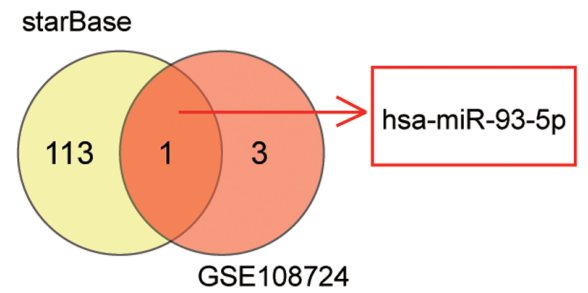

C

C mimic-NC $\square$ miR-93-5p mimic
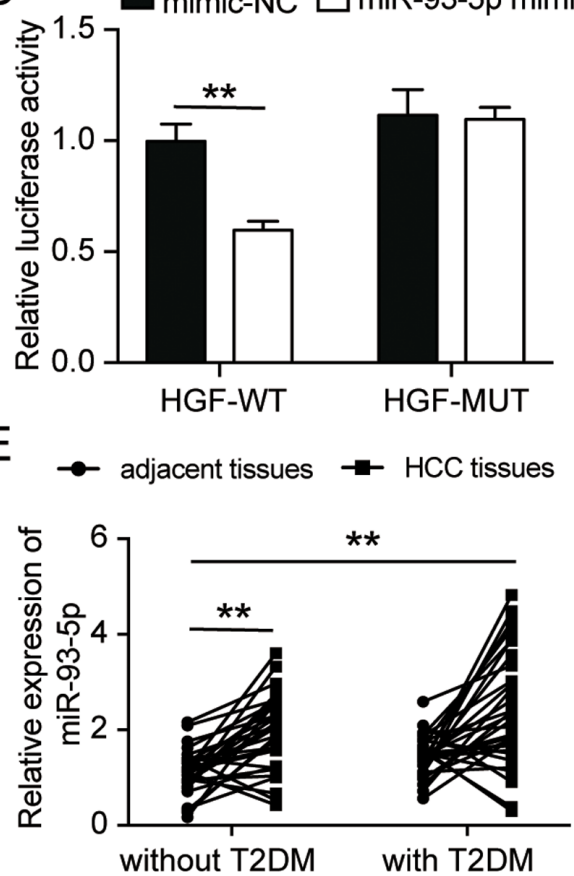

G

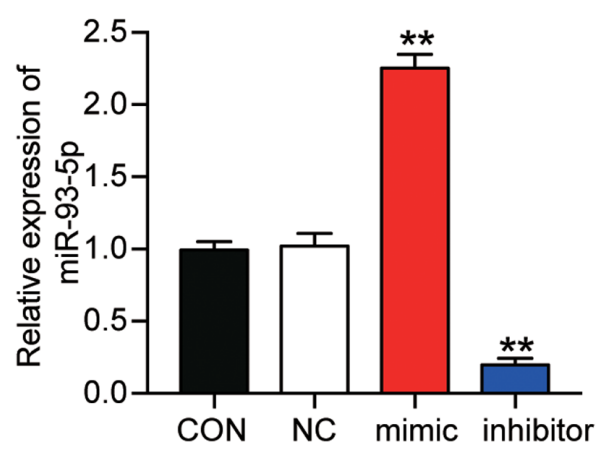

B

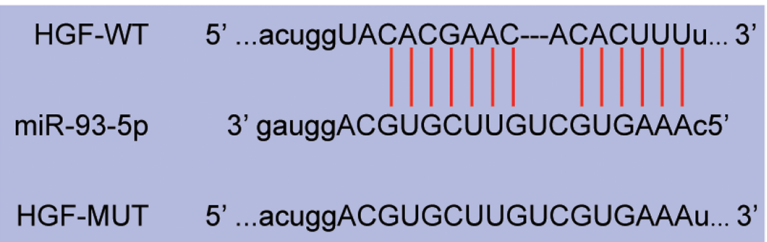

D

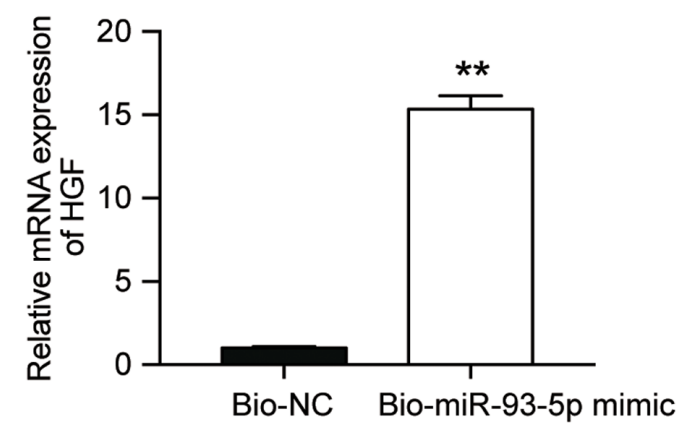

F

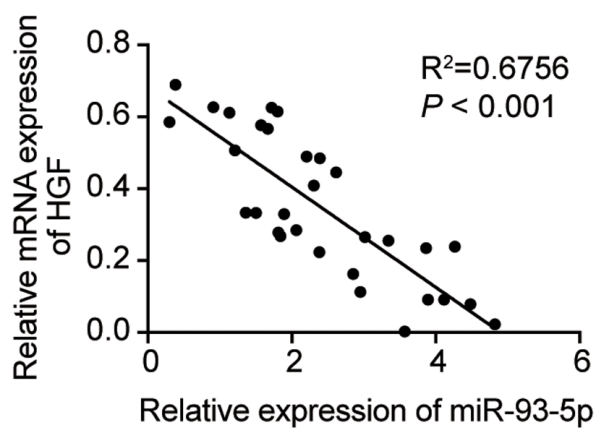

$\mathrm{H}$

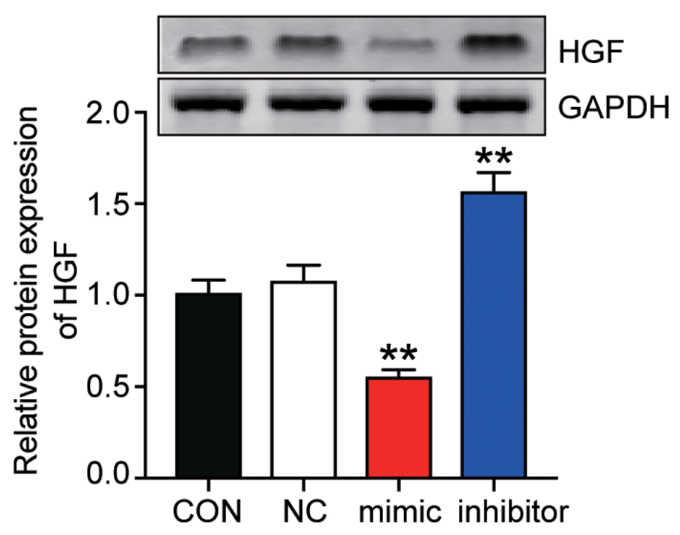

Figure 3. HGF is a downstream target gene of miR-93-5p in HepG2 cells. (A) miR-93-5p was the only overlapping miRNA between the GSE108724 dataset and starBase analyses. GSE108724 is a miRNA expression microarray. starBase was used to predict the miRNAs targeting HGF. (B) starBase was used to predict the binding sites between HGF and miR-93-5p. (C) Dual-luciferase reporter assays were performed to assess the interaction between HGF and miR-93-5p. ${ }^{* *} \mathrm{P}<0.001$. (D) RNA pull-down assays were conducted to verify the target relationship between HGF and miR-93-5p. (E) miR-93-5p expression levels in HCC tissues and adjacent healthy tissues isolated from patients with or without T2DM. (F) Pearson's correlation coefficient analysis was performed to assess the correlation between miR-93-5p expression and HGF expression. (G) miR-93-5p expression levels in insulin-resistant HepG2 cells following transfection with miR-93-5p inhibitor or miR-93-5p mimic. (H) HGF protein expression levels in insulin-resistant HepG2 cells following transfection with miR-93-5p inhibitor or miR-93-5p mimic. Data are presented as the mean \pm SD. ${ }^{* *} \mathrm{P}<0.001$ vs. CON. HGF, hepatocyte growth factor; miR/miRNA, microRNA; T2DM, type 2 diabetes mellitus; WT, wild-type; MUT, mutant; NC, negative control (mimic-NC + inhibitor-NC); HCC, hepatocellular carcinoma; CON, blank control.

resistance $(36,37)$. Therefore, it was hypothesized that HGF might participate in the regulation of insulin resistance and T2DM in HepG2 cells.

In the present study, the results demonstrated that HGF suppressed the tumor phenotype progression of HepG2 cells, which was consistent with previous studies on other types of cancer, such as bladder, head and neck, and cervical cancer (32-34). Moreover, the results indicated that HGF decreased insulin resistance in HepG2 cells, which was also consistent with previous studies $(36,37)$. Therefore, the present study identified HGF as a potential molecule that protected against HCC and T2DM. 

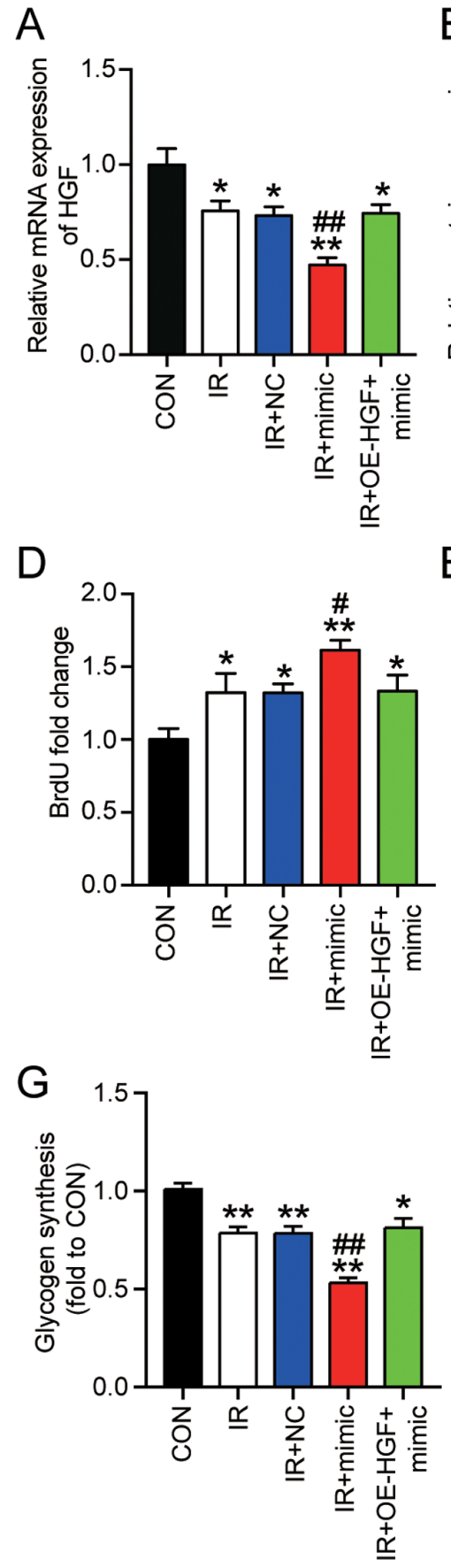

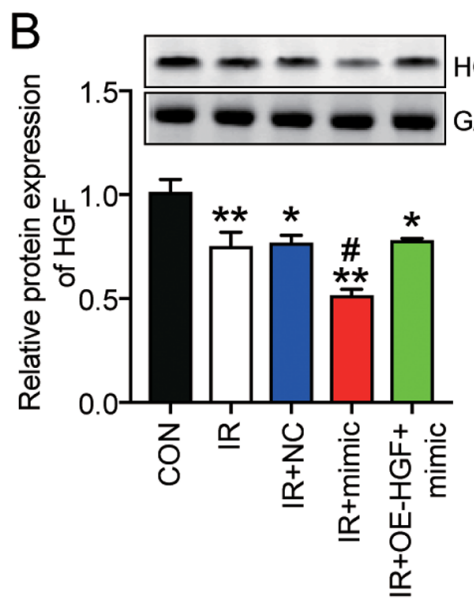

C
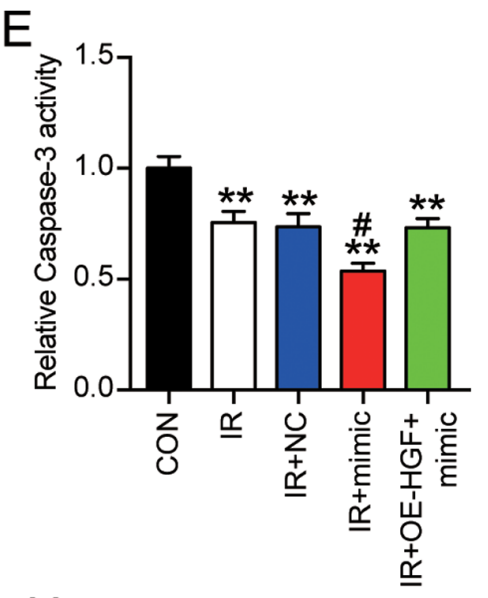

$\mathrm{H}$
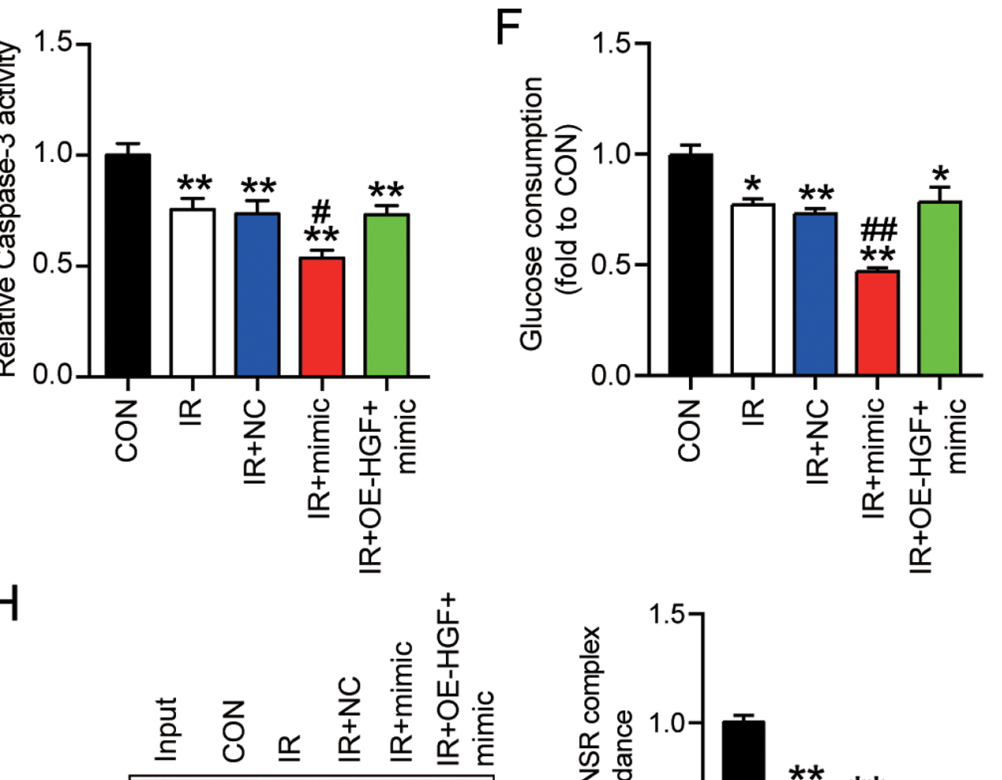

IB: Met

IB: INSR

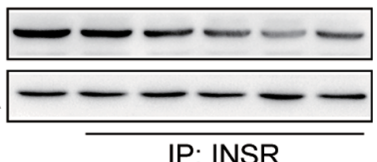

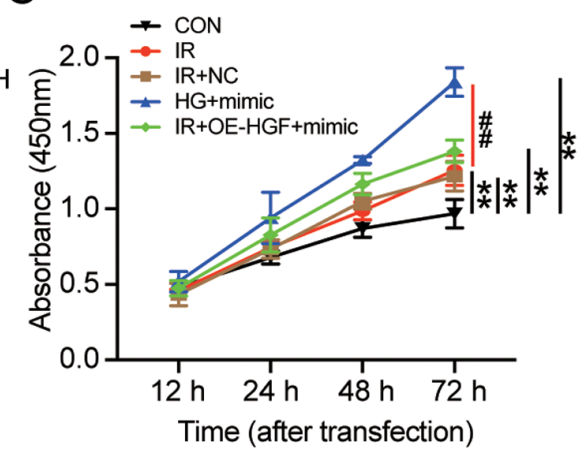

Time (after transfection)

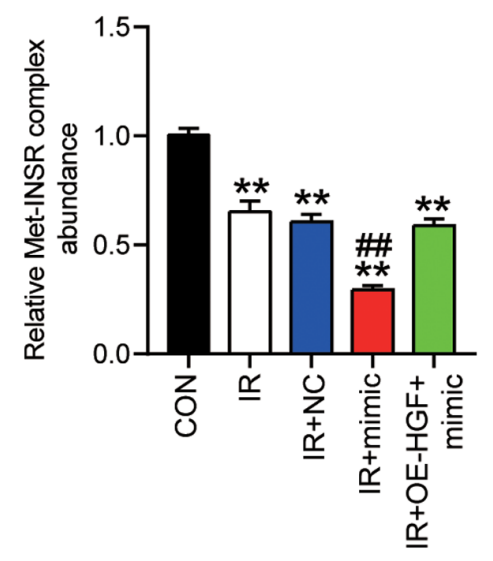

Figure 4. miR-93-5p promotes insulin resistance to regulate the progression of HepG2 cells by targeting HGF. Insulin-resistant HepG2 cells were transfected with miR-93-5p mimic or miR-93-5p mimic + OE-HGF. HGF (A) mRNA and (B) protein expression levels were measured via reverse transcription-quantitative PCR and western blotting, respectively. Cell (C) viability, (D) proliferation (E) apoptosis, (F) glucose consumption and (G) glycogen synthesis were assessed by performing Cell Counting Kit-8, BrdU, caspase-3 activity, glucose consumption and glycogen synthesis assays, respectively. (H) Met-INSR complex abundance was assessed by performing immunoprecipitation assays. Data are presented as the mean $\pm \mathrm{SD}$. ${ }^{*} \mathrm{P}<0.05$ and ${ }^{* * *} \mathrm{P}<0.001$ vs. CON; ${ }^{*} \mathrm{P}<0.05$ and ${ }^{\# \#} \mathrm{P}<0.001$ vs. IR. miR, microRNA; HGF, hepatocyte growth factor; OE, overexpression; Met-INSR, Met-insulin receptor; CON, blank control; IR, insulin resistance; $\mathrm{NC}$, negative control (mimic-NC + pcDNA3.1).

miRNAs are a class of regulatory molecules that affect glucose metabolism and cancer development $(19,38)$. The bioinformatics analysis conducted in the present study indicated that miR-93-5p might target HGF and participate in the development of liver cancer. Based on the literature, miR-93-5p has been reported to serve considerable roles in tumorigenesis in multiple types of cancer, including gastric cancer (39), small cell lung cancer (40), and squamous cell carcinoma of the head and neck (41). The aforementioned studies demonstrated that miR-93-5p promoted tumorigenesis. Apart from its tumorigenesis role, miR-93-5p also enhanced human HCC cell proliferation $(22,42)$. Given the mutually promoting action between human HCC and insulin resistance triggered T2DM, it was hypothesized that miR-93-5p might mediate the occurrence of insulin resistance in HCC cell lines. Similar to previous studies, the results of the present study demonstrated that compared with the IR group, miR-93-5p mimic significantly promoted cell proliferation, 
but significantly inhibited cell apoptosis in insulin-resistant HepG2 cells, which indicated a tumor promoting effect of miR-93-5p in HCC. Furthermore, in the present study, several assays, including glucose consumption and glycogen synthesis assays, were performed to determine the role of miR-93-5p in insulin resistance. miR-93-5p expression was significantly increased in HCC tissues isolated from patients with T2DM compared with adjacent tissues isolated from patients without T2DM. Moreover, the results indicated that miR-93-5p promoted insulin resistance in HepG2 cells. Furthermore, the results of the present study indicated that miR-93-5p mediated its effects on insulin-resistant HepG2 cells by inhibiting HGF.

The present study had a number of limitations. First, the effect of the miR-93-5p/HGF axis on insulin resistance in vivo was not assessed. In future studies, an appropriate animal model should be constructed to assess the effect of the miR-93-5p/HGF axis on insulin resistance in vivo. Moreover, the present study only used HCC cell lines and tissues isolated from patients with HCC, which made it difficult to assess whether the proposed mechanism was only suitable for patients with diabetes. According to the results of the present study, HGF expression was downregulated and miR-93-5p expression was upregulated in HCC tissues with or without T2DM compared with adjacent healthy hepatic tissues of patients with HCC without T2DM. Although the results did not entirely represent the expression patterns of HGF and miR-93-5p in patients with T2DM and healthy controls, the results suggested that there might be a similar regulatory mechanism in patients with T2DM alone.

In summary, the present study suggested that miR-93-5p enhanced insulin resistance to regulate T2DM progression in HepG2 cells by targeting HGF. The results of the present study further suggested that miR-93-5p or HGF might serve as novel therapeutic targets for T2DM.

\section{Acknowledgements}

Not applicable.

\section{Funding}

No funding was received.

\section{Availability of data and materials}

The datasets used and/or analyzed during the current study are available from the corresponding author on reasonable request.

\section{Authors' contributions}

DG designed the study. MZ, YH, JW and GL performed the experiments. PC, WC and $\mathrm{LH}$ performed the experiments and drafted the manuscript. JW and GL confirm the authenticity of all the raw data. All authors read and approved the final manuscript.

\section{Ethics approval and consent to participate}

The present study was approved by the Ethics Committee of Wuhan Third Hospital (approval no. KY2020-015). All patients provided written informed consent.

\section{Patient consent for publication}

Not applicable.

\section{Competing interests}

The authors declare that they have no competing interests.

\section{References}

1. Triplitt CL: Examining the mechanisms of glucose regulation. Am J Manag Care 18 (Suppl 1): S4-S10, 2012.

2. Chatterjee S, Khunti K and Davies MJ: Type 2 diabetes. Lancet 389: 2239-2251, 2017.

3. Petersen MC and Shulman GI: Mechanisms of insulin action and insulin resistance. Physiol Rev 98: 2133-2223, 2018.

4. Chan JC, Malik V, Jia W, Kadowaki T, Yajnik CS, Yoon KH and Hu FB: Diabetes in Asia: Epidemiology, risk factors, and pathophysiology. JAMA 301: 2129-2140, 2009.

5. Riddy DM, Delerive P, Summers RJ, Sexton PM and Langmead CJ: G Protein-coupled receptors targeting insulin resistance, obesity, and type 2 diabetes mellitus. Pharmacol Rev 70: 39-67, 2018.

6. Li G, Zhou F, Chen Y, Zhang W and Wang N: Kukoamine A attenuates insulin resistance and fatty liver through downregulation of Srebp-1c. Biomed Pharmacother 89: 536-543, 2017.

7. von Horn C and Minor T: Modern concepts for the dynamic preservation of the liver and kidneys in the context of transplantation. Pathologe 40: 292-298, 2019 (In German).

8. El-Serag HB, Hampel H and Javadi F: The association between diabetes and hepatocellular carcinoma: a systematic review of epidemiologic evidence. Clin Gastroenterol Hepatol 4: 369-380, 2006

9. Polesel J, Zucchetto A, Montella M, Dal Maso L, Crispo A, La Vecchia C, Serraino D, Franceschi S and Talamini R: The impact of obesity and diabetes mellitus on the risk of hepatocellular carcinoma. Ann Oncol 20: 353-357, 2009.

10. Ueki T, Kaneda Y, Tsutsui H, Nakanishi K, Sawa Y, Morishita R, Matsumoto K, Nakamura T, Takahashi H, Okamoto E, et al: Hepatocyte growth factor gene therapy of liver cirrhosis in rats. Nat Med 5: 226-230, 1999.

11. Fafalios A, Ma J, Tan X, Stoops J, Luo J, Defrances MC and Zarnegar R: A hepatocyte growth factor receptor (Met)-insulin receptor hybrid governs hepatic glucose metabolism. Nat Med 17: 1577-1584, 2011.

12. Zhang YY, Li C, Yao GF, Du LJ, Liu Y, Zheng XJ, Yan S, Sun JY, Liu Y, Liu MZ, et al: Deletion of Macrophage Mineralocorticoid Receptor Protects Hepatic Steatosis and Insulin Resistance Through ER $\alpha /$ HGF/Met Pathway. Diabetes 66: 1535-1547, 2017.

13. Oliveira AG, Araújo TG, Carvalho BM, Rocha GZ, Santos A and Saad MJ: The role of hepatocyte growth factor (HGF) in insulin resistance and diabetes. Front Endocrinol (Lausanne) 9: $503,2018$.

14. Li Z, Xu R and Li N: MicroRNAs from plants to animals, do they define a new messenger for communication? Nutr Metab (Lond) 15: 68, 2018.

15. Reinhart BJ, Weinstein EG, Rhoades MW, Bartel B and Bartel DP: MicroRNAs in plants. Genes Dev 16: 1616-1626, 2002.

16. Nicolai S, Pieraccioli M, Smirnov A, Pitolli C, Anemona L, Mauriello A, Candi E, Annicchiarico-Petruzzelli M, Shi Y, Wang Y, et al: ZNF281/Zfp281 is a target of miR-1 and counteracts muscle differentiation. Mol Oncol 14: 294-308, 2020.

17. Bartel DP: MicroRNAs: Genomics, biogenesis, mechanism, and function. Cell 116: 281-297, 2004.

18. FischerC,SekiT,LimS,NakamuraM,Andersson P,Yang Y,HonekJ Wang Y, Gao Y, Chen F, et al: A miR-327-FGF10-FGFR2-mediated autocrine signaling mechanism controls white fat browning. Nat Commun 8: 2079, 2017.

19. Trajkovski M, Hausser J, Soutschek J, Bhat B, Akin A, Zavolan M, Heim MH and Stoffel M: MicroRNAs 103 and 107 regulate insulin sensitivity. Nature 474: 649-653, 2011.

20. Pardo F, Villalobos-Labra R, Sobrevia B, Toledo F and Sobrevia L: Extracellular vesicles in obesity and diabetes mellitus. Mol Aspects Med 60: 81-91, 2018. 
21. Thurnherr T, Mah WC, Lei Z, Jin Y, Rozen SG and Lee CG: Differentially expressed miRNAs in hepatocellular carcinoma target genes in the genetic information processing and metabolism pathways. Sci Rep 6: 20065, 2016.

22. Wang X, Liao Z, Bai Z, He Y, Duan J and Wei L: MiR-93-5p Promotes cell proliferation through down-regulating PPARGC1A in hepatocellular carcinoma cells by bioinformatics analysis and experimental verification. Genes (Basel) 9: 9, 2018.

23. Aravinthan A, Challis B, Shannon N, Hoare M, Heaney J and Alexander GJ: Selective insulin resistance in hepatocyte senescence. Exp Cell Res 331: 38-45, 2015.

24. Williams JF and Olefsky JM: Defective insulin receptor function in down-regulated HepG2 cells. Endocrinology 127: 1706-1717, 1990.

25. Wang H, Huo X, Yang XR, He J, Cheng L, Wang N, Deng X, Jin $\mathrm{H}$, Wang $\mathrm{N}$, Wang $\mathrm{C}$, et al: STAT3-mediated upregulation of IncRNA HOXD-AS1 as a ceRNA facilitates liver cancer metastasis by regulating SOX4. Mol Cancer 16: 136, 2017.

26. Darpolor MM, Basu SS, Worth A, Nelson DS, ClarkeKatzenberg RH, Glickson JD, Kaplan DE and Blair IA: The aspartate metabolism pathway is differentiable in human hepatocellular carcinoma: Transcriptomics and (13) C-isotope based metabolomics. NMR Biomed 27: 381-389, 2014.

27. Schmidt JA, Avarbock MR, Tobias JW and Brinster RL: Identification of glial cell line-derived neurotrophic factor-regulated genes important for spermatogonial stem cell self-renewal in the rat. Biol Reprod 81: 56-66, 2009.

28. Zhu HR, Yu XN, Zhang GC, Shi X, Bilegsaikhan E, Guo HY, Liu LL, Cai Y, Song GQ, Liu TT, et al: Comprehensive analysis of long non coding RNA messenger RNA microRNA co expression network identifies cell cycle related lncRNA in hepatocellular carcinoma. Int J Mol Med 44: 1844-1854, 2019.

29. Livak KJ and Schmittgen TD: Analysis of relative gene expression data using real-time quantitative PCR and the 2(-Delta Delta C(T)) method. Methods 25: 402-408, 2001

30. Tsai S, Clemente-Casares X, Zhou AC, Lei H, Ahn JJ, Chan YT, Choi O, Luck H, Woo M, Dunn SE, et al: Insulin Receptor-Mediated Stimulation Boosts T Cell Immunity during Inflammation and Infection. Cell Metab 28: 922-934.e4, 2018.

31. Mantovani A and Targher G: Type 2 diabetes mellitus and risk of hepatocellular carcinoma: Spotlight on nonalcoholic fatty liver disease. Ann Transl Med 5: 270, 2017.

32. Sim WJ, Iyengar PV, Lama D, Lui SKL, Ng HC, Haviv-Shapira L, Domany E, Kappei D, Tan TZ, Saei A, et al: c-Met activation leads to the establishment of a TGF $\beta$-receptor regulatory network in bladder cancer progression. Nat Commun 10: 4349, 2019.

33. Hartmann S, Bhola NE and Grandis JR: HGF/Met Signaling in head and neck cancer: Impact on the tumor microenvironment. Clin Cancer Res 22: 4005-4013, 2016.
34. Boromand N, Hasanzadeh M, ShahidSales S, Farazestanian M, Gharib M, Fiuji H, Behboodi N, Ghobadi N, Hassanian SM, Ferns GA, et al: Clinical and prognostic value of the C-Met/HGF signaling pathway incervical cancer.JCell Physiol 233: 4490-4496, 2018.

35. Coudriet GM, Stoops J, Orr AV, Bhushan B, Koral K, Lee S, Previte DM, Dong HH, Michalopoulos GK, Mars WM, et al: A noncanonical role for plasminogen activator inhibitor type 1 in obesity-induced diabetes. Am J Pathol 189: 1413-1422, 2019.

36. Muratsu J, Iwabayashi M, Sanada F, Taniyama Y, Otsu R, Rakugi H and Morishita R: Hepatocyte growth factor prevented high-fat diet-induced obesity and improved insulin resistance in mice. Sci Rep 7: 130, 2017.

37. Bertola A, Bonnafous S, Cormont M, Anty R, Tanti JF, Tran A, Le Marchand -Brustel Y and Gual P: Hepatocyte growth factor induces glucose uptake in 3T3-L1 adipocytes through A Gab1/phosphatidylinositol 3-kinase/Glut4 pathway. J Biol Chem 282: 10325-10332, 2007.

38. Calin GA and Croce CM: MicroRNA signatures in human cancers. Nat Rev Cancer 6: 857-866, 2006.

39. Ma DH, Li BS, Liu JJ, Xiao YF, Yong X, Wang SM, Wu YY, Zhu HB, Wang DX and Yang SM: miR-93-5p/IFNAR1 axis promotes gastric cancer metastasis through activating the STAT3 signaling pathway. Cancer Lett 408: 23-32, 2017.

40. Huang W, Yang Y, Wu J, Niu Y, Yao Y, Zhang J, Huang X, Liang S Chen R, Chen S, et al: Circular RNA cESRP1 sensitises small cell lung cancer cells to chemotherapy by sponging miR-93-5p to inhibit TGF- $\beta$ signalling. Cell Death Differ 27: 1709-1727, 2020.

41. Zhang S, He Y, Liu C, Li G, Lu S, Jing Q, Chen X, Ma H, Zhang D, Wang Y, et al: miR-93-5p enhances migration and invasion by targeting RGMB in squamous cell carcinoma of the head and neck. J Cancer 11: 3871-3881, 2020.

42. Chen C, Zheng Q, Kang W and Yu C: Long non-coding RNA LINC00472 suppresses hepatocellular carcinoma cell proliferation, migration and invasion through miR-93-5p/PDCD4 pathway. Clin Res Hepatol Gastroenterol 43: 436-445, 2019.

43. Vauthey JN, Lauwers GY, Esnaola NF, Do KA, Belghiti J, Mirza N, Curley SA, Ellis LM, Regimbeau JM, Rashid A, et al: Simplified staging for hepatocellular carcinoma. J Clin Oncol 20: $1527-1536,2002$

This work is licensed under a Creative Commons Attribution-NonCommercial-NoDerivatives 4.0 International (CC BY-NC-ND 4.0) License. 